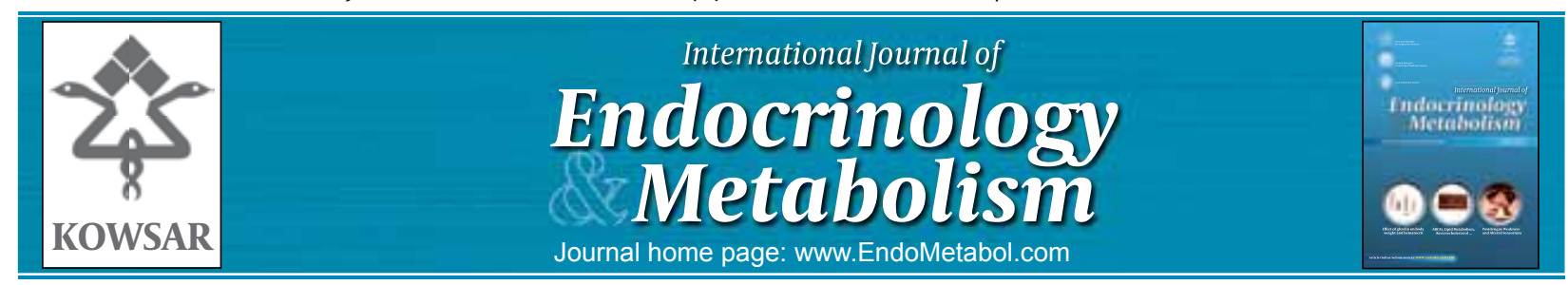

\title{
Assessment of Cognitive Function, Mood, and Quality of Life in Hypopituitary Patients After Pituitary Adenomectomy With or Without Radiotherapy
}

\author{
Carolina Petry ${ }^{1}$, Maria Carolina Rios ${ }^{1}$, Carolina Garcia Soares Leaes ${ }^{1}$, Julia Fernanda \\ Semmelmman Pereira-Lima ${ }^{1}$, Miriam da Costa Oliveira ${ }^{1^{*}}$ \\ ${ }^{1}$ Center for Neuroendocrinology, Santa Casa Hospital Complex, University of Health Sciences of Port Alegre (UFCSPA), Porto Alegre, Brazil
}

\begin{tabular}{l}
\hline A R T I C L E I N F O \\
\hline Article type: \\
Original Article \\
\hline Article history: \\
Received: 12 Jan 2011 \\
Revise: 03 Feb 2011 \\
Accepted: 22 Mar 2011 \\
\hline
\end{tabular}

Keywords:

Pituitary Gland

Hypophysectomy

Hypopituitarism

Radiotherapy

\begin{abstract}
A B S T R A C T
Background: Pituitary diseases are often associated with changes in quality of life. Hypopituitarism and radiotherapy may negatively affect quality of life, causing depression and anxiety and resulting in cognitive disorders.

Objectives: To comparatively evaluate cognitive function and quality of life in patients with pituitary adenomas who developed hypopituitarism after surgery, with or without radiotherapy.

Patients and Methods: Out of a total of 36 patients enrolled in the study, 25 (70\%) received conformal radiotherapy as an adjuvant treatment. The mean age was $47 \pm 13$ years in the radiotherapy group and $48 \pm 12$ years in the non-radiotherapy group. All the patients had hypopituitarism and had undergone hormone replacement therapy, with the exception of the growth hormone, for the entire axes. Tests to assess cognitive function, anxiety, depression, and quality of life were performed on an outpatient basis.

Results: There were no differences between the groups, with respect to gender, educational level, and presence of deficit in the adrenal, gonadal, somatotropic, or thyroid axis. Mean time since surgery and that since radiotherapy was $10 \pm 5$ years and $10 \pm 6$ years, respectively. All the patients had some degree of anxiety and depression on the basis of their Beck Anxiety and Depression Inventory scores. There was a trend toward greater depression severity in the group undergoing radiotherapy $(p=0.058)$. With respect to the health-related quality of life, a significant difference was detected in social relationships, with lower scores observed in the radiotherapy group.

Conclusions: Irradiated hypopituitary patients showed impairment in the social relationship aspect of their quality of life and greater depression severity.
\end{abstract}

Copyright $\odot 2011$ Kowsar M.P. Co. All rights reserved.

Implication for health policy/practice/research/medical education:

There is a lack of clinical studies and reviews specifically evaluating the role of surgical hypopituitarism and radiotherapy in the HQOL, mood, and cognitive function of patients.

\section{Please cite this paper as:}

Petry C; Rios MC; Leaes CGS; Pereira-Lima JFS; Oliveira Mdc, Assessment of Cognitive Function, Mood, and Quality of Life in Hypopituitary Patients After Pituitary Adenomectomy With or Without Radiotherapy. Int J Endocriol Metab.2011;9(2):306-10.

DOI: 10.5812/kowsar.1726913X.2597

* Corresponding author: Miriam da Costa Oliveira, Rua Dona Mimi Moro, 40 90480-050, Porto Alegre, RS, Brazil. Tel: + 55-5133039000, Fax: +555133038810,E-mail: mco@portoweb.com.br

DOI:10.5812/kowsar.1726913X.2597

Copyright $\odot 2011$ Kowsar M.P.Co. All rights reserved.

\section{Background}

Pituitary adenomas account for $5-20 \%$ of all brain tumors (1). Therapeutic options for these tumors include surgery, drug treatment, and radiotherapy, either alone or in combination. Pituitary diseases are often associa- 
ted with changes in health-related quality of life (HQOL). Hypopituitarism, specifically, can negatively affect HQOL and cause depression and anxiety, leading to cognitive disorders (2). Surgical insult to the pituitary gland is a risk factor for the development of hypopituitarism, with 7.2$20.6 \%$ of patients presenting new pituitary deficiencies after a trans-sphenoidal approach, even in experienced surgical centers (3). Growth hormone (GH)- and corticotropin (ACTH)-secreting adenomas are associated with persistent adverse effects that may affect HQOL, even in cured patients $(4,5)$. Radiotherapy can lead to the development of hypopituitarism in more than $80 \%$ of the cases 10 years after irradiation (6). Since new deficiencies can appear even 20 years later, lifelong surveillance is necessary and has been related to reduced $\operatorname{HQOL}(7,8)$. There is a lack of clinical studies and reviews specifically evaluating the role of surgical hypopituitarism and radiotherapy in the HQOL, mood, and cognitive function of patients.

\section{Objectives}

The objective of this study was to evaluate cognitive function and HQOL in pituitary adenoma patients who developed hypopituitarism after surgery. The patients were classified into the radiotherapy group (on the basis of the patient's condition prior to surgery [impossibility of total resection] and response to surgery) and the nonradiotherapy group.

\section{Patients and Methods}

\subsection{Subject Selection and Questionnaire}

A sample chosen by convenience included a total of 36 patients who were operated on via the trans-sphenoidal route by the same neurosurgeon in a reference neurosurgery hospital. The patients were selected upon follow-up in the Center for Neuroendocrinology in our institution. Twenty-five patients (70\%) received fractionated conformal radiotherapy as adjuvant treatment, at doses of 45-50 Gy. The mean age was $47 \pm 13$ years in the radiotherapy group and $48 \pm 12$ years in the non-radiotherapy group. All the patients had hypopituitarism and had undergone hormone replacement therapy, with the exception of $\mathrm{GH}$, for the entire axis. The exclusion criteria were aspects that could hinder tests, such as illiteracy, blindness, and motor disability. The patients gave written informed consent and answered a questionnaire that included information on educational level, time since surgery, time since radiotherapy (if applicable), and hormone replacement therapy. Tests for the assessment of cognitive function (mini-mental state examination [MMSE]) (9,10), digit span (DS) (11,12), word span (WS) (11, $12)$, famous faces (13), immediate recall $(14,15)$, anxiety (Beck Anxiety Inventory [BAI]) (16), depression (Beck Depression Inventory [BDI]) (16), and HQOL (an abbreviated Portuguese version of the World Health Organization Quality of Life Assessment Instrument [WHOQOL-BREF]) (17) were then applied on an outpatient basis. Patients answered the tests individually, in the absence of relatives or caregivers. The examiner read the questions aloud for patients with some degree of visual impairment, and no patient received aid in the interpretation of the questions. All the assessments were performed and analyzed by the same trained examiner (CP). The study was approved by the local ethics committee (Institutional Review Board-equivalent) and conducted in accordance with the provisions of the Declaration of Helsinki.

\subsection{Statistical Analysis}

The analyzed data followed univariate normal distribution, which allowed us to use parametric tests. Quantitative data and cognitive scores were expressed as mean and standard deviation values and categorical variables as counts and percentage values. The Student $t$ test was used for comparisons between mean values, and the chisquare test (or Fisher's exact test) was used for categorical data. The significance level was set at $5 \%(p<0.05)$, and the Statistical Package for the Social Sciences (SPSS) version 17.0 was used for data analysis.

\section{Results}

The demographic characteristics of all the study patients are described in Table 1. There were no differences

\begin{tabular}{|c|c|c|c|}
\hline & $\begin{array}{l}\text { Surgery + RT }{ }^{\mathbf{a}} \\
(\mathbf{n}=\mathbf{2 5})\end{array}$ & $\begin{array}{l}\text { Surgery } \\
(\mathbf{n}=11)\end{array}$ & $P^{a}$ Value \\
\hline Age, $y$ & $47 \pm 13$ & $49 \pm 12$ & - \\
\hline $\operatorname{Sex}, \mathrm{F}^{\mathrm{a}} / \mathrm{M}^{\mathrm{a}}$ & $16 / 9$ & $5 / 6$ & 0.46 \\
\hline GH $^{\mathrm{a}} /$ IGF-1 $^{\mathrm{a}}$ deficit $^{\mathrm{b}}$ & $28.6 \%$ & $33.3 \%$ & 1.00 \\
\hline $\mathrm{LH}^{\mathrm{a}} / \mathrm{FSH}^{\mathrm{a}}$ deficit & $64.0 \%$ & $54.5 \%$ & 0.71 \\
\hline $\mathrm{ACTH}^{\mathrm{a}}$ deficit & $68.0 \%$ & $63.6 \%$ & 1.00 \\
\hline Thyroid deficit & $68.0 \%$ & $100 \%$ & 0.07 \\
\hline 3 or more deficits ${ }^{c}$ & $44.0 \%$ & $45.5 \%$ & 1.00 \\
\hline
\end{tabular}

a Abbreviations: RT, radiotherapy; $p$, significance level; $\mathrm{F}$, female; $\mathrm{M}$, male; $\mathrm{GH}$, growth hormone; IGF-1, insulin-like growth factor; LH, luteinizing hormone; FSH, follicle-stimulating hormone; and ACTH, adrenocorticotropic hormone

${ }^{\mathrm{b}}$ Documented assessment of GH or IGF-1 available in 10 cases

${ }^{\mathrm{c}}$ Three or more hypophyseal axes deficits

between groups with respect to gender, educational level, and presence of deficit in the adrenal, gonadal, somatotropic, or thyroid axis, although thyroid deficiency showed a trend toward significance $(p<0.076)$. The assessment of concomitant deficiency in 3 or more hormonal axes also revealed no differences between groups. When the tests were performed, the mean time since surgery or since the first surgery, if there were multiple surgeries, was $10 \pm 5$ years (2-25 years), and the mean time since radiotherapy was $10 \pm 6$ years (1-25 years). Of the 36 patients, 18 (50\%) were diagnosed with nonfunctioning adenoma, 12 (33\%) with GH-secreting adenoma, 5 
(14\%) with prolactin-producing adenoma, and 1 (3\%) with ACTH-producing adenoma (Cushing's disease). The results for cognitive function, anxiety, and depression are shown in Table 2.

\begin{tabular}{llll}
\hline \multicolumn{4}{l}{ Table 2. Results for Cognitive Function and Anxiety and Depression Scores } \\
\hline Tests & $\begin{array}{l}\text { Surgery+RT } \\
\text { (Mean Score) }\end{array}$ & $\begin{array}{l}\text { Surgery } \\
\text { (Mean Score) }\end{array}$ & $\mathbf{P}^{\mathbf{a}}$ Value \\
\hline MMSE $^{\mathrm{a}}$ & 23.50 & 26.70 & 0.17 \\
$\mathrm{DS}^{\mathrm{a}}$ & 6.00 & 6.00 & 1.00 \\
$\mathrm{WS}^{\mathrm{a}}$ & 5.00 & 6.18 & 0.67 \\
Famous faces & 21.12 & 25.09 & 0.06 \\
$\mathrm{Immediate} \mathrm{recall}^{\text {Im }}$ & 4.52 & 4.27 & 0.78 \\
$\mathrm{BAI}^{\mathrm{a}}$ & 9.96 & 9.73 & 0.96 \\
$\mathrm{BDI}^{\mathrm{a}}$ & 14.28 & 8.27 & 0.058 \\
\hline
\end{tabular}

${ }^{a}$ Abbreviations: RT, radiotherapy; $p$, significance level; MMSE, Mini-mental state examination; DS, digit span; WS, word span; BAI, Beck Anxiety Inventory; and BDI, Beck Depression Inventory

MMSE revealed no differences between the radiotherapy and non-radiotherapy groups with respect to specific cognitive functions such as orientation to time, orientation to place, 3-word registration, attention and calculation, 3-word recall, language, and visual constructive ability $(p=0.17)$. The mean DS score also showed no significant differences between the 2 groups. The mean WS score was 5.0 words in the radiotherapy group and 6.18 words in the non-radiotherapy group, and both groups showed satisfactory performance. Both groups showed good performance on the famous faces test, with no statistically significant differences between the groups. In the immediate recall test, both groups could recall about 4 fragments of the story, thereby showing a satisfactory performance.

The study patients had some degree of anxiety, according to their BAI scores. In the radiotherapy group, 19 patients had minimal level of anxiety, 1 had mild anxiety, 4 had moderate anxiety, and 1 had severe anxiety, whereas in the non-radiotherapy group, 9 patients had minimal anxiety, 1 had mild anxiety, and 1 had moderate anxiety; no differences were observed between the 2 groups $(p=$ 0.96). Likewise, all the study patients had some degree of depression, according to their BDI scores. In the radiotherapy group, 15 patients had minimal depression, 2 had mild depression, 6 had moderate depression, and 2 had severe depression; and in the non-radiotherapy group, 9 patients had minimal depression, 1 had mild depression, and 1 had moderate depression. In the radiotherapy group, the mean BDI score was 14.28 (mild depression) versus 8.27 (minimal depression) in the nonradiotherapy group, with a trend toward greater depression severity in the group administered radiotherapy ( $p$ $=0.058$ ). The results of WHOQOL-BREF are described in Table 3. A significant difference was detected in the social relationships, with the radiotherapy group showing lower scores than the non-radiotherapy group.

\begin{tabular}{llll}
\hline Table 3. Results of the Health-Related Quality of Life (HQOL) Assessment \\
\hline $\begin{array}{l}\text { WHOQOL-BREF } \\
\text { Domains }\end{array}$ & $\begin{array}{l}\text { Surgery+RT } \\
\text { (MeanScores) }^{\mathbf{a}}\end{array}$ & $\begin{array}{l}\text { Surgery } \\
\text { (Mean Scores) }\end{array}$ & $\boldsymbol{P}^{\mathbf{a}}$ Value \\
\hline Physical health & 58.85 & 64.9 & 0.24 \\
Psychological & 62.8 & 68.18 & 0.38 \\
Social relationships & 60.33 & 72 & 0.04 \\
Environment & 58 & 63.6 & 0.30 \\
\hline
\end{tabular}

a Abbreviations: RT, radiotherapy; $p$, significance level; and WHOQOLBREF, World Health Organization Quality of Life Assessment Instrument

\section{Discussion}

In patients with pituitary adenoma, mass effects of the tumor, surgical intervention, or radiotherapy can lead to hypopituitarism. Regardless of the cause, hypopituitarism was a constant variable in the sample group. In the assessment of cognition, the mean MMSE scores based on the educational level range from 22 to 28 (18). The mean scores in our hypopituitary radiotherapy and nonradiotherapy groups were within this range.

The overall performance on memory tests was satisfactory. Even though our group of patients did not undergo GH therapy, the findings of our study disagreed with those obtained by Bülow et al (7), who showed impaired cognitive function in female hypopituitary patients who did not undergo GH replacement therapy, in a setting similar to that in this study. Our findings also disagreed with those obtained by Nieves-Martinez et al. (19), who reported that GH deficit plays a role in memory and attention impairment. Our findings indicated that patients performed the range of tests without significant impairment in cognitive function.

Pituitary adenomas per se may have a strong impact on patients for different reasons such as the following: the tumor's proximity to the central nervous system, indication for surgery in this specific area, consecutive therapies as deemed necessary, adverse effects of treatment, consequences of hormone deficiency that may be present since diagnosis, consequences of hormone hypersecretion in secreting adenomas, physical abnormalities resulting from acromegaly and Cushing's disease, longterm medical follow-up and assessments (necessary even in successful cases), and a high rate of tumor recurrence. This list certainly does not exhaust the adverse events associated with pituitary adenomas but allows us to predict mood and HQOL changes.

In this study, all the patients had some degree of anxiety and depression. The mean BAI score in a sample of university students was 11.4 , and $4 \%$ of the sample showed a pathological level of stress (20). Our patients had mean scores closer to those described in the normal population, which range from 4.18 to 10.69 , with differences according to gender and urban or rural dwelling (21). In our study, non-irradiated patients showed mean BDI scores within this range, whereas BDI scores were higher among irradiated patients (21), with a strong trend to- 
ward a difference between the 2 groups. The findings in relation to general population HQOL scores have yet to be fully established. General data for the different WHOQOLBREF domains are as follows: $73.5 \pm 18.1$ for the physical health domain; $70.6 \pm 14.0$ for psychological well-being; $71.5 \pm 18.2$ for social relationships; and $75.1 \pm 13.0$ for the environment domain (21). In our study, mean scores, in most cases, were lower than the above-mentioned scores, although within standard deviation values. The finding of low scores in the field of social relationships in the irradiated patients in this study is intriguing and has an undefined effect on the day-to-day lives of the patients. A previous study showed that the scores of unhealthy individuals were up to $50 \%$ lower than those of healthy subjects (22). Other studies reported that discontinuation of GH therapy in young adults with childhood-onset GH deficiency leads to a decrease in HQOL (23).

The groups evaluated in the present study, due to their descriptive characteristics, although not analyzed separately by gender, proved to be an adequate sample for the purpose of identifying radiotherapy-induced effects on cognition, depression, anxiety, and HQOL effects that include hypopituitarism itself. All surgeries had been performed via trans-sphenoidal access and with minimal pituitary damage by the same neurosurgeon in a reference neurosurgery hospital (3). The regimen and dose of radiotherapy used were those most commonly recommended for pituitary adenomas (8). Our findings are not consistent with those by Burman et al. (24), who reported deleterious effects of conventional radiotherapy on brain function and showed that GH deficiency was not a determinant factor for brain injury. Similarly, Peace et al. (25) reported cognitive impairment, especially in memory function and reading ability, in irradiated patients. Radiation therapy may lead to cognitive impairment attributable to either vascular injury in small-and medium-sized blood vessels (26) or to an autoimmune process triggered by damaged glial cells (27). Conversely, similar to our study, Noad et al. (28) reported that although patients undergoing radiotherapy may show impaired function while executing tasks, they do not have overall cognitive impairment. A review by Brada and Jankowska (29) failed to show clear evidence that low-dose fractioned radiotherapy, in addition to the deleterious effects of surgery and the tumor itself, affects cognitive function in adults. Tooze et al. (30) suggested a need for further studies to assess cognitive status at the time of diagnosis of pituitary adenoma and periodically during follow-up. The same approach was recommended by Fernandez et al. (8), who observed that hypopituitarism may develop even 20 years after radiotherapy, indicating the need for long-term monitoring in order to diagnose and treat new deficiencies. There is much debate on the specific role of radiotherapy in mood changes. According to Page et al. (31), patients who had received radiotherapy were more depressed and showed greater anxiety. Our results did not confirm these findings, although a trend toward greater depression severity was detected in the radiotherapy group. In contrast, radiotherapy has already been observed to exert a mild protective effect against depression (32).

There is much debate on the effect of radiotherapy on HQOL. Van Beek et al. (33) did not observe reduced HQOL in the irradiated group in a study of 82 patients with nonfunctioning pituitary adenoma who were treated using radiotherapy and hormone replacement therapy for the involved axis. Likewise, Noad et al. (28) did not detect reduced HQOL among irradiated patients. Conversely, Dekkers et al. (34) reported reduced HQOL in patients successfully treated for pituitary adenomas by radiotherapy when the Short Form-36 was applied, an impairment detected in our study only in the social relationships domain of WHOQOL-BREF. Our results showed that patients with hypopituitarism associated with pituitary adenomas did not show cognitive impairment, memory deficit, or different anxiety scores. Impairment was detected only in 2 categories: depression, with greater depression severity among irradiated patients and HQOL, in which irradiated patients showed a deficit in the social relationship domain. It is important to mention that our study consisted of patients who had undergone trans-sphenoidal surgery, whereas postsurgical pituitary dysfunction occurs more commonly in patients who undergo craniotomy (3).

The advent of modern radiotherapy has contributed to improved survival and HQOL in patients with a variety of malignancies and benign tumors, albeit with an increased risk of treatment-related adverse effects (8). Since our findings do not reflect the consensus in the literature, a re-evaluation conducted in different pre- and post-surgical and pre- and post-radiotherapy settings and in the presence or absence of hypopituitarism may point toward an association of each of these variables, with possible cognitive impairment or mood and HQOL changes.

\section{References}

1. Arafah BM, Nasrallah MP. Pituitary tumors: pathophysiology, clinical manifestations and management. Endocr Relat Cancer. 2001;8(4):287-305

2. Burman P, Deijen JB. Quality of life and cognitive function in patients with pituitary insufficiency. Psychother Psychosom. 1998;67(3):154-67.

3. Nomikos P, Ladar C, Fahlbusch R, Buchfelder M. Impact of primary surgery on pituitary function in patients with non-functioning pituitary adenomas a study on 721 patients. Acta Neurochir (Wien). 2004;146(1):27-35.

4. Biermasz NR, van Thiel SW, Pereira AM, Hoftijzer HC, van Hemert AM, Smit JW, et al. Decreased quality of life in patients with acromegaly despite long-term cure of growth hormone excess. J Clin Endocrinol Metab. 2004;89(11):5369-76.

5. Van Aken MO, Pereira AM, Biermasz NR, van Thiel SW, Hoftijzer HC, Smit JW, et al. Quality of life in patients after long-term biochemical cure of Cushing's disease. J Clin Endocrinol Metab. 2005;90(6):3279-86.

6. Toogood AA, Ryder WD, Beardwell CG, Shalet SM. The evolution of radiation-induced growth hormone deficiency in adults is determined by the baseline growth hormone status. Clin Endocrinol (Oxf). 1995;43(1):97-103.

7. Bulow B, Hagmar L, Orbaek P, Osterberg K, Erfurth EM. High 
incidence of mental disorders, reduced mental well-being and cognitive function in hypopituitary women with GH deficiency treated for pituitary disease. Clin Endocrinol (Oxf). 2002;56(2):18393.

8. Fernandez A, Brada M, Zabuliene L, Karavitaki N, Wass JA. Radiation-induced hypopituitarism. Endocr Relat Cancer. 2009;16(3):733-72.

9. Almeida OP. [Mini mental state examination and the diagnosis of dementia in Brazil]. Arq Neuropsiquiatr. 1998;56(3B):605-12.

10. Laks J, Baptista EM, Contino AL, de Paula EO, Engelhardt E. MiniMental State Examination norms in a community-dwelling sample of elderly with low schooling in Brazil. Cad Saude Publica. 2007;23(2):315-9.

11. Baddeley A, Hitch G. Working memory. In: Bower G, editor. Recent advances in learning and motivation. New York: Academic Press; 1974 . p. p. 47-89.

12. Santos FH, Bueno OF. Validation of the Brazilian Children's Test of Pseudoword Repetition in Portuguese speakers aged 4 to 10 years. Braz J Med Biol Res. 2003;36(11):1533-47.

13. Rizzo S, Venneri A, Papagno C. Famous face recognition and naming test: a normative study. Neurol Sci. 2002;23(4):153-9.

14. Schultz RR, Siviero MO, Bertolucci PH. The cognitive subscale of the "Alzheimer's Disease Assessment Scale" in a Brazilian sample. Braz J Med Biol Res. 2001;34(10):1295-302.

15. Prince M, Acosta D, Chiu H, Scazufca M, Varghese M. Dementia diagnosis in developing countries: a cross-cultural validation study. Lancet. 2003;361(9361):909-17.

16. Gorenstein C, Andrade L. Validation of a Portuguese version of the Beck Depression Inventory and the State-Trait Anxiety Inventory in Brazilian subjects. Braz J Med Biol Res. 1996;29(4):453-7.

17. Fleck MP, Louzada S, Xavier M, Chachamovich E, Vieira G, Santos L, et al. [Application of the Portuguese version of the abbreviated instrument of quality life WHOQOL-bref]. Rev Saude Publica. 2000;34(2):178-83.

18. Crum RM, Anthony JC, Bassett SS, Folstein MF. Population-based norms for the Mini-Mental State Examination by age and educational level. JAMA. 1993;269(18):2386-91.

19. Nieves-Martinez E, Sonntag WE, Wilson A, Donahue A, Molina DP, Brunso-Bechtold J, et al. Early-onset GH deficiency results in spatial memory impairment in mid-life and is prevented by GH supplementation. J Endocrinol. 2010;204(1):31-6.

20. Armando M, Dario C, Righetti V, Saba R, Cavaggioni G, Lia C, et al [Depressive and anxiety symptoms in a community sample of young adults and correlation with help-seeking behavior]. Clin Ter. 2010;161(2):e25-32.

21. Veerman JL, Dowrick C, Ayuso-Mateos JL, Dunn G, Barendregt JJ. Population prevalence of depression and mean Beck Depression Inventory score. Br J Psychiatry. 2009;195(6):516-9.
22. Hawthorne G, Herrman H, Murphy B. Interpreting the WHOQOLBref: Preliminary population norms and effect sizes. Soc Indicators Res. 2006;77:37-59.

23. Stouthart PJ, Deijen JB, Roffel M, Delemarre-van de Waal HA. Quality of life of growth hormone (GH) deficient young adults during discontinuation and restart of GH therapy. Psychoneuroendocrinology. 2003;28(5):612-26.

24. Burman P, Broman JE, Hetta J, Wiklund I, Erfurth EM, Hagg E, et al. Quality of life in adults with growth hormone (GH) deficiency: response to treatment with recombinant human $\mathrm{GH}$ in a placebo-controlled 21-month trial. J Clin Endocrinol Metab. 1995;80(12):3585-90.

25. Peace KA, Orme SM, Padayatty SJ, Godfrey HP, Belchetz PE. Cognitive dysfunction in patients with pituitary tumour who have been treated with transfrontal or transsphenoidal surgery or medication. Clin Endocrinol (Oxf). 1998;49(3):391-6.

26. Burger PC, Mahley MS, Jr., Dudka L, Vogel FS. The morphologic effects of radiation administered therapeutically for intracranial gliomas: a postmortem study of 25 cases. Cancer. 1979;44(4):125672.

27. Glass JP, Hwang TL, Leavens ME, Libshitz HI. Cerebral radiation necrosis following treatment of extracranial malignancies. Cancer. 1984;54(9):1966-72.

28. Noad R, Narayanan KR, Howlett T, Lincoln NB, Page RC. Evaluation of the effect of radiotherapy for pituitary tumours on cognitive function and quality of life. Clin Oncol (R Coll Radiol). 2004;16(4):233-7.

29. Brada M, Jankowska P. Radiotherapy for pituitary adenomas. Endocrinol Metab Clin North Am. 2008;37(1):263-75.

30. Tooze A, Gittoes NJ, Jones CA, Toogood AA. Neurocognitive consequences of surgery and radiotherapy for tumours of the pituitary. Clin Endocrinol (Oxf). 2009;70(4):503-11.

31. Page RC, Hammersley MS, Burke CW, Wass JA. An account of the quality of life of patients after treatment for non-functioning pituitary tumours. Clin Endocrinol (Oxf). 1997;46(4):401-6.

32. Peace KA, Orme SM, Sebastian JP, Thompson AR, Barnes S, Ellis A et al. The effect of treatment variables on mood and social adjustment in adult patients with pituitary disease. Clin Endocrinol (Oxf). 1997;46(4):445-50.

33. van Beek AP, van den Bergh AC, van den Berg LM, van den Berg G, Keers JC, Langendijk JA, et al. Radiotherapy is not associated with reduced quality of life and cognitive function in patients treated for nonfunctioning pituitary adenoma. Int J Radiat Oncol Biol Phys. 2007;68(4):986-91.

34. Dekkers OM, van der Klaauw AA, Pereira AM, Biermasz NR, Honkoop PJ, Roelfsema F, et al. Quality of life is decreased after treatment for nonfunctioning pituitary macroadenoma. J Clin Endocrinol Metab. 2006;91(9):3364-9. 